\title{
Vertical Guided Bone Regeneration using Titanium-reinforced d-PTFE Membrane and Prehydrated Corticocancellous Bone Graft
}

\author{
Alessandro Cucchi ${ }^{1}$ and Paolo Ghensi ${ }^{2, *}$ \\ ${ }^{I}$ Department of Biomedical and Neuromotorial Science, University of Bologna, Bologna, Italy. Private Practice, Man- \\ tova $(M N)$, Italy \\ ${ }^{2}$ Department of Neuroscience, University of Padova, Padova, Italy. Private Practice, Trento (TN), Italy
}

\begin{abstract}
Guided bone regeneration (GBR) standard protocols call for filling the space underneath the membrane with autogenous bone or a mixture composed of autogenous bone particles and allogeneic bone tissue or heterologous biomaterials. This work describes the case of a GBR performed to restore a vertical bone defect with simultaneous placement of a dental implant in the posterior mandible that was carried out using a high density d-PTFE membrane and corticocancellous porcine-derived bone without the addition of any autogenous bone. Bone regeneration was assessed by histological analysis of a biopsy sample collected from the grafted site nine months after the surgery. Intraoral radiographs taken at follow-up visits showed complete maintenance of the peri-implant bone levels for up to two years after prosthesis delivery. The regenerated site successfully supported functional loading of the implant. The present case report suggests that the use of a heterologous bone substitute alone to restore a vertical defect in a GBR procedure can be as effective as the standard protocol, while avoiding the drawbacks associated with a second surgical site opening.
\end{abstract}

Keywords: Guided bone regeneration, heterologous biomaterials, vertical bone augmentation

\section{INTRODUCTION}

The successful outcome of osseointegrated implants relies on a sufficient bone quantity for their stabilization. However, this condition is not always satisfied in clinical practice. Lack of bone volume may be due to congenital, post-traumatic, or post-surgical defects. Alternatively, as a result of the increased bone resorption that follows tooth loss, severe reduction of the residual ridges may occur in the wake of total or partial edentulism $[1,2]$. In all these situations, bone grafting may be needed. At present a variety of materials and surgical techniques are available for augmenting local jaw bone horizontally or vertically including osteodistraction, inlay and onlay bone grafting, inferior alveolar nerve transposition, and guided bone regeneration (GBR) techniques [3].

The GBR procedure calls for the application of a membrane to the bone defect to prevent non-osteogenic cell populations of the surrounding soft tissues from entering and populating the regenerating site $[4,5]$. Osteogenic cells residing in the osseous wound then can proliferate and differentiate, promoting the restoration of the osseous defect [6, 7]. Since the introduction of this procedure, a number of technical variations have been introduced. A wide range of

*Address correspondence to this author at the Department of Neuroscience, University of Padova, Padova, Italy. Private Practice, Trento (TN), Italy; Tel: +393494539969; E-mail: dr.ghensi@gmail.com bioresorbable and non-resorbable membrane materials have been tested in experimental and clinical studies, including polytetrafluoroethylene (PTFE), expanded PTFE (ePTFE), titanium mesh membranes, collagen, poly(lactic acid), poly(glycolic acid), and their copolymers [8-12]. Every membrane type has both advantages and disadvantages. Recently a high-density polytetrafluoroethylene (dPTFE) membrane has been designed specifically for bone-augmentation procedures. The dPTFE is cell occlusive, shows minimal inflammation when exposed to the oral cavity, and does not integrate with the tissue for membrane stabilization [13]. Clinical and histological evidence for the use of dPTFE membranes is limited [14-17]. Some indications can be found concerning its use in guided tissue regeneration and guided bone regeneration in immediate implant-placement sites and fresh extraction sockets $[18,19]$.

A number of attempts have been made to enhance bone regeneration by positioning various bone graft materials under the membrane. The intent is to preserve and maintain the space under the membrane and prevent its collapse by providing mechanical support. At first the potential of autogenous bone was explored [20, 21]. Autogenous bone is still considered the gold standard for most applications, including GBR, because it contains osteocytes, stem cells and growth factors that have superior osteogenic and osteoinductive properties. However the need for a second surgery to harvest autogenous bone, its limited availability, and concerns about donor-site morbidity and graft resorption all affect its use [3]. 


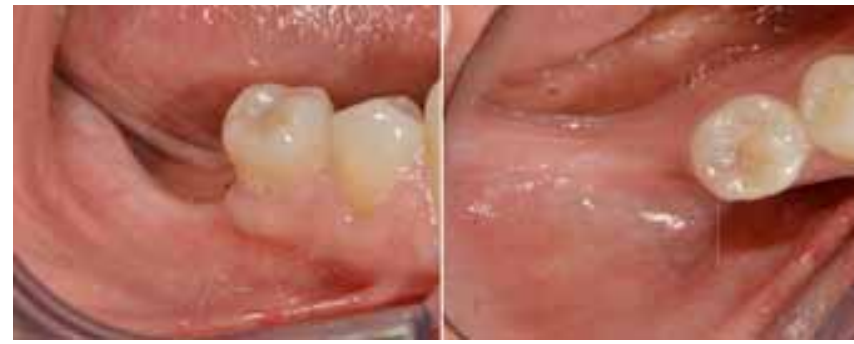

Fig. (1). Pre-operative intraoral examination (a). Teeth 46 an 47 are lacking (b).

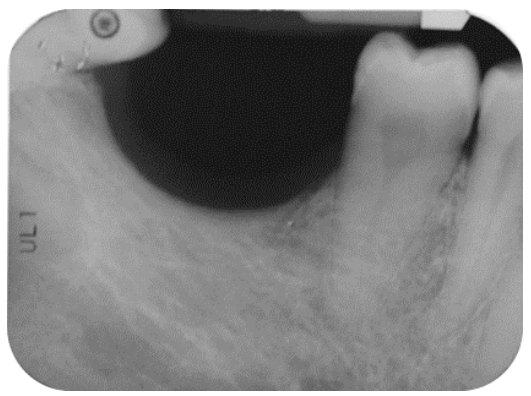

Fig. (2). Endoral radiograph. The corresponding alveolar ridge shows a severe vertical atrophy.

Subsequent clinical investigations have demonstrated that allogeneic bone grafts in conjunction with GBR procedures can be a viable alternative to autogenous grafts [22-24]. Used both alone and in combination with autogenous bone, allografts have the advantages of being easily available in unlimited quantity and obviating the need for a second surgery. The major limitation is that they must be tested for the presence of any transmittable infectious agent and processed to prevent any risk of antigenicity or disease transmission $[25,26]$. To overcome the limitations associated with autografts and allografts, heterologous bone substitutes (mainly bovine, porcine, or equine-derived) have been introduced to the GBR procedure as fill materials in in vivo experiments performed on animal models and later in patients [27-31]. Such bone substitutes, which are usually mixed with autogenous bone particles, have provided predictable results in local augmentation of jawbone [22, 32, 33]. One study evaluating the clinical performance of a 50:50 deproteinized bovine bone mineral (DBBM) and autogenous bone graft in vertical ridge augmentation surgeries showed that the quality of the regeneration obtained with the bony mixture was suitable for the successful insertion of dental implants at the recipient site, both simultaneously and in a two-step surgery [34].

The following case report presents the use of the GBR technique to restore a mandibular first molar in a site with significant vertical resorption. A single implant was placed with high torque, and the peri-implant bone defect was filled exclusively with heterologous porcine-derived graft material. The site was then covered with a non-resorbable d-PTFE titanium-reinforced membrane.

\section{CASE REPORT}

The patient was a non-smoking, 55-year-old man with a non-contributory medical history who presented seeking to

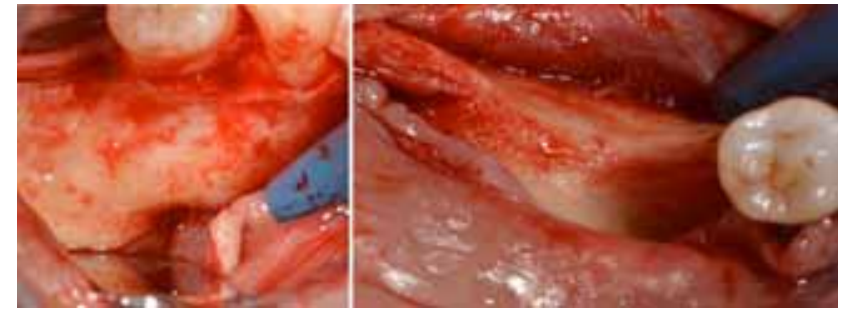

Fig. (3). Flap preparation. Mental nerve isolation (a) and alveolar ridge exposure (b).
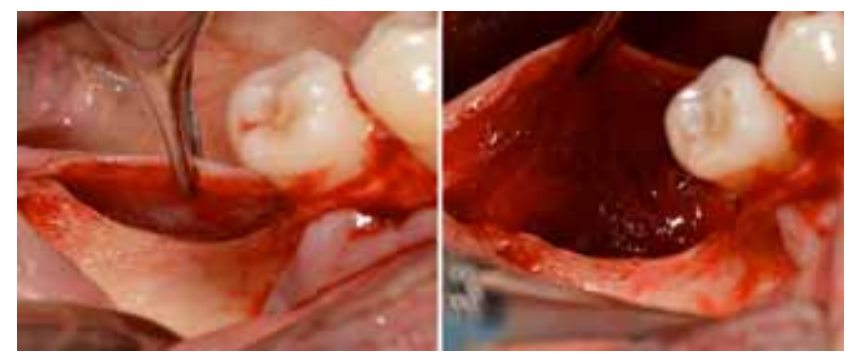

Fig. (4). Flap preparation. Lingual flap isolation (a); the mylohyoid muscle insertion is removed and flap released (b).

improve his masticatory function on the lower right side of his mouth. A comprehensive intraoral examination was performed to assess his overall oral health. The patient was missing teeth 46 and 47 (Fig. 1a, 1b); clinical and radiographic examination revealed a severe vertical defect of the corresponding alveolar ridge (Fig. 2). After assessing the periodontal status of the adjacent teeth, a treatment plan was developed calling for a GBR procedure and simultaneous placement of a dental implant. The patient provided informed consent.

For antibiotic prophylaxis, $2 \mathrm{~g}$ of amoxicillin (Zimox, Pfizer Inc., USA) were administered 1 hour before surgery. The patient also rinsed for 2 minutes with chlorhexidine $0.20 \%$ mouth rinse (Curasept ADS $^{\circledR} 220$, Curaprox , Switzerland) and received $100 \mathrm{mg}$ of a non-steroidal-antiinflammatory drug (Aulin, Hoffmann-La Roche, Switzerland). Local anesthetic was administered by means of infiltration into the oral mucosa with $4 \%$ Articain hydrochloride with epinephrine 1:100000 (Oralbloc, Pierrel S.p.A, Italy).

A mid-crestal full-thickness incision was created within the keratinized mucosa of the edentulous ridge, extending it to tooth 44 through an intrasulcular incision and performing two vertical incisions to prepare a trapezoidal mucoperiosteal flap. The flap was then elevated to expose the right posterior sector of the mandible. On the buccal side, the inferior mental nerve was isolated, and the flap was released with a horizontal periosteal incision to provide passive adaptation (Fig. 3a, 3b). On the lingual side, the flap was elevated until reaching the mylohyoid line (Fig. 4a). Then, using a blunt instrument, it was localized a connective tissue band continuing with the epimysium of the mylohyoid muscle. This band is usually located in the first molar area and inserted into the inner part of the lingual flap approximately $5 \mathrm{~mm}$ from the crest in an apical direction. The blunt instrument was therefore positioned below the connective band, and with gentle traction in the coronal direction, the muscular insertion was detached from the lingual flap (Fig. 4b). 


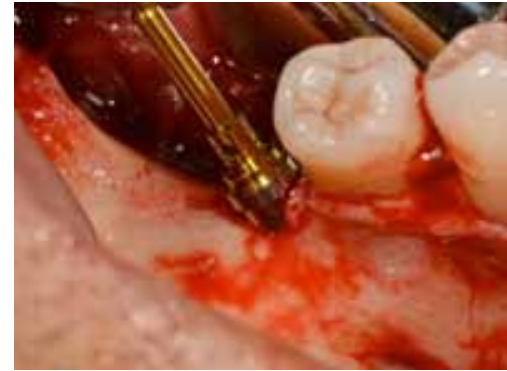

Fig. (5). Implant-like pin in position.
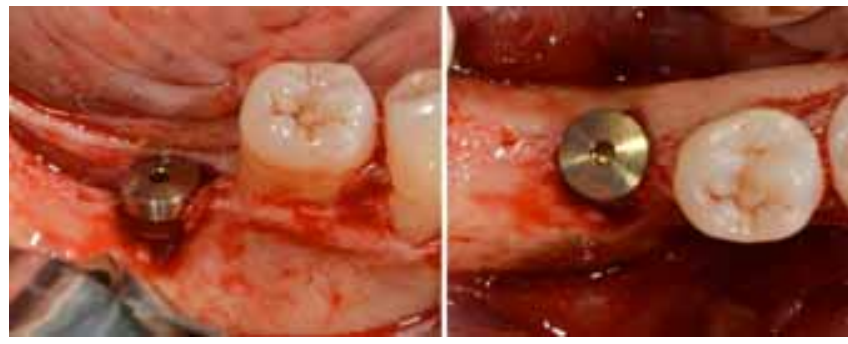

Fig. (6). Positioned dental implant with a cower screw on it in frontal (a) and occlusal (b) views.

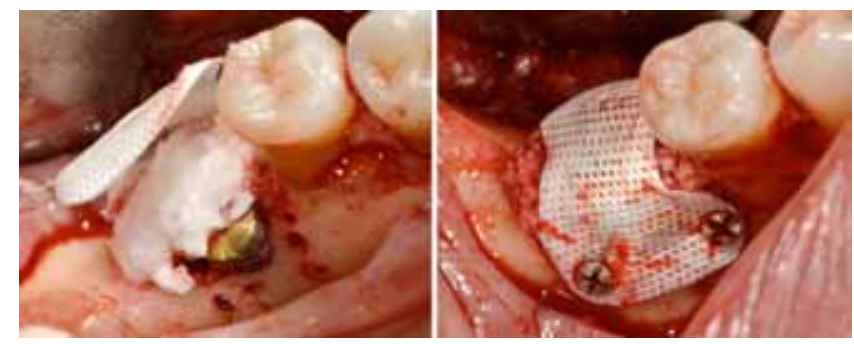

Fig. (7). Positioning of the high density d-PTFE titaniumreinforced membrane to cover the grafted site. Heterologous porcine-derived biomaterial positioned to fill the peri-implant defect and to support the membrane (a); note the series of holes on the vestibular surface performed to induce bleeding and trigger bone regeneration. Definitive membrane fixing (b).

Given the severe vertical alveolar bone defect, the implant site was underprepared. An $8 \mathrm{~mm}$ long pilot hole was drilled, and a $5 \mathrm{~mm}$ wide and $11.5 \mathrm{~mm}$ long implant (BT KONIC Implant, Biotec BTK, Italy) was placed (Fig. 5). Its platform on the ideal line was located $2 \mathrm{~mm}$ below the cementoenamel junction (CEJ) of the adjacent teeth but 2.5 $\mathrm{mm}$ above the alveolar ridge because of the vertical bone defect in the first molar region (Fig. 6). The insertion torque was $70 \mathrm{Ncm}$, confirming the implant's good primary stability. The peri-implant bone defect resulting from the alveolar atrophy and underpreparation was filled using a heterologous bone material made of corticocancellous porcine bone particles prehydrated with collagen gel (OsteoBiol mp3, Tecnoss Dental, Italy).

To obtain profuse bleeding from the marrow of the bone graft recipient sites, a series of holes were drilled on the vestibular and crestal bone surfaces in zone 46, using a round bur with a diameter of $1.2 \mathrm{~mm}$ (Fig. 7a, 7b). A nonresorbable high-density polytetrafluoroethylene (d-PTFE) titanium-reinforced membrane (Cytoplast ${ }^{\circledR}$ Ti-250, Osteohealth, USA) was then positioned over the implant and fixed

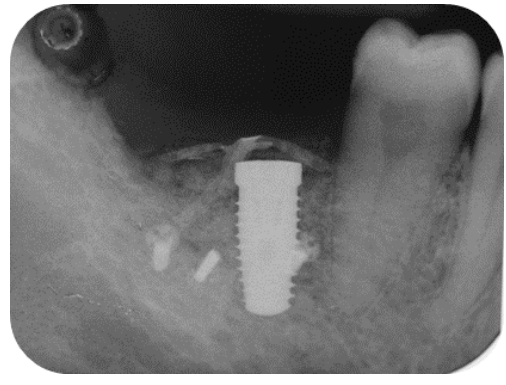

Fig. (8). Post-surgical endoral $x$-ray showing the correct implant positioning and bone defect restoration.
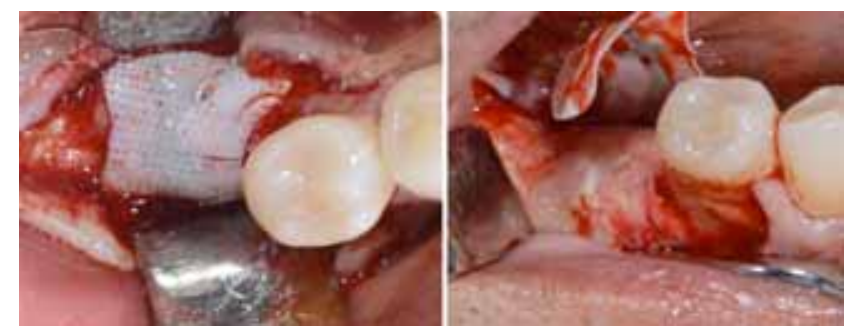

Fig. (9). Second surgery showing the membrane retrieval (a) and the uneventful healing of the recipient site (b).
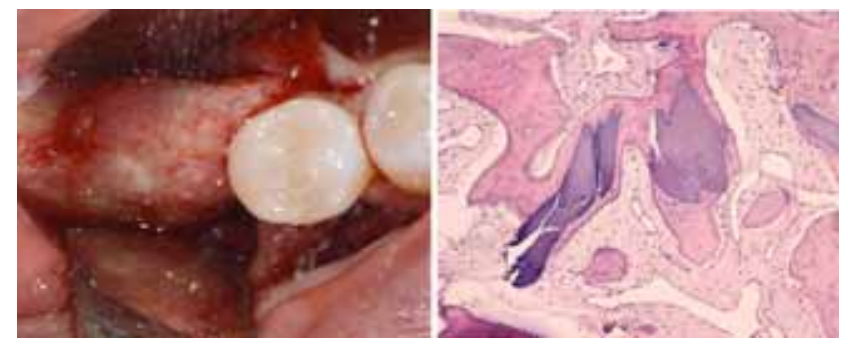

Fig. (10). The uneventful healing of the recipient site (a). Histological analysis of the biopsy collected at the regenerating site showing the presence of acidophilic bone tissue in close contact with basophilic graft material and no fibrous tissue interposition. Osteocytes in the lacunae indicate that the acidophilic tissue is newly-formed vital bone (b).

through a manual screwdriver with four mini-screws to cover the defect and isolate it from the surrounding soft tissues. The mucoperiostal flaps were tested for their passivity and their ability to cover the augmented area. Complete flap closure was achieved using a non-resorbable suture (Cytoplast ${ }^{\circledR}$ 4-0 PTFE Monofilament Suture, Osteogenics Biomedical, USA) in order to facilitate soft-tissue healing and avoid early or late membrane exposure.

Radiographic examination was performed to verify correct implant positioning and bone- defect restoration (Fig. 8). The patient was instructed to consume a soft diet and avoid mastication in the area of surgery for the first 6 weeks. In addition, he was told to rinse twice a day with $0.2 \%$ chlorhexidine mouthwash and avoid brushing the surgical site for the first 2 weeks. Amoxicillin $1 \mathrm{~g}$ every 8 hours was prescribed for 1 week and non-steroidal-anti-inflammatory (Aulin, Hoffmann-La Roche, Switzerland) drugs for 5 days.

The re-entry surgery was accomplished nine months later. The screws were removed, and the membrane was retrieved (Fig. 9a, 9b, 10a). A biopsy sample was collected 


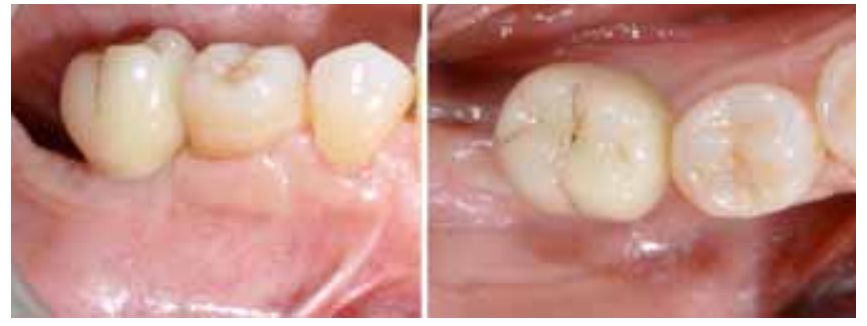

Fig. (11). Single-crown definitive restoration in frontal (a) and occlusal (b) views.

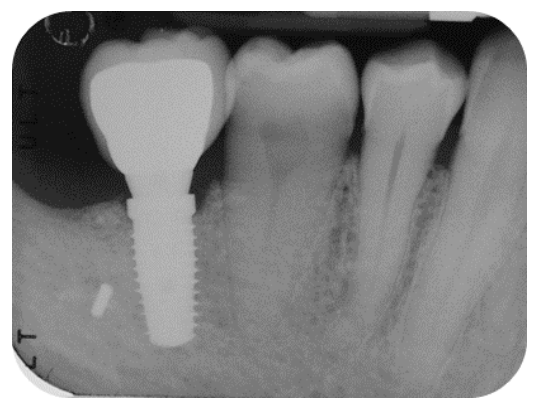

Fig. (12). Follow-up x-ray at 1-month.

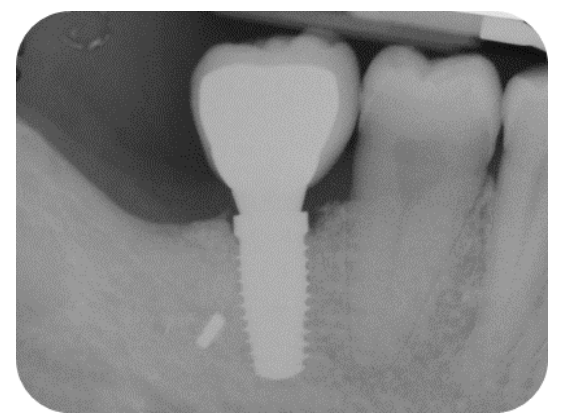

Fig. (13). Follow-up x-ray at 12-months.

buccodistally in respect of the implant, using a $3.8 \mathrm{~mm}$ external diameter trephine. The sample was fixed in $10 \%$ buffered formalin, decalcified with $10 \%$ formic acid, dehydrated in an ascending concentration series of ethanol (50\%, 70\% and $100 \%$ ), embedded in paraffin resin, and then cut with a microtome into $4 \mu \mathrm{m}$ sections. After hematoxylin-eosin staining, slides were observed under an optical microscope with transmitted light to analyze bone tissue and assess bone formation at the grafted site (Fig. 10b).

After 15 days, the soft-tissue healing was uneventful, and the previously established prosthetic protocol was followed. A single-crown definitive restoration was delivered 1 month (Fig. 11a, 11b). The prosthesis was placed in occlusion, where the occlusal surface was thoroughly modeled, so that it was in contact with reduced areas during laterality and protrusion excursions, in order to reduce the dislocating vectorial components; more contacts were maintained in maximum intercuspation. Follow-up radiographs were taken at 1, 12, and 24 months after prosthesis delivery (Fig. 12, 13, 14).

The patient healed uneventfully, with no clinical signs of soft-tissue inflammation or recession and, as recommended in the GBR protocol, no membrane exposure. At the time of the second-stage surgery, the implant appeared completely

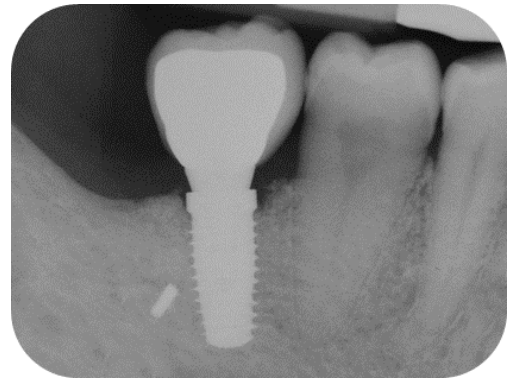

Fig. (14). Follow-up x-ray at 24 months displaying the stable maintenance of the peri-implant bone tissue levels and no sign of bone resorption.

submerged in bony tissue. No graft volume appeared to have been lost during the healing period. Implant stability was checked with a reverse-torque test at $25 \mathrm{Ncm}$.

Histological analysis of the bone sections showed the presence of acidophilic bone tissue. As the bone core was harvested at the graft site, and numerous osteocytes were observed in the lacunae, it is reasonable to infer that this well-structured bone was newly formed vital bone. No complete substitution had occurred, since basophilic graft material was also present. Such material was in close contact with the vital bone, and no fibrous tissue interposition was found, indicating respectively that the biomaterial was osseointegrated and biocompatible.

One year after surgery, clinical examination showed no significant changes in the soft-tissue contours. All follow-up radiographs taken up to 24 months after implant placement showed complete maintenance of the peri-implant bone levels without any sign of bone resorption. The grafted site was perfectly able to support the functional loading of the implant.

\section{DISCUSSION}

In dentistry a vertical bone defect is defined as a onesided bone resorption of $2 \mathrm{~mm}$ or more of the interdental marginal bone apical to the alveolar crest. This periodontal destruction has a right-left symmetric distribution within the maxilla and mandible, but it is more common in the posterior than the anterior [35]. Both the prevalence and severity of vertical bone defects increase with age, and when extensive, they can compromise the adequate placement of dental implants and the required angulation [36, 37].

In such cases, the dentist is faced with the dilemma of whether to augment the bone or to use short implants $(8 \mathrm{~mm}$ or less). Various techniques are currently used to augment the posterior mandibles and maxillae $[3,10]$. The techniques used for vertically augmenting posterior mandibles are vertical guided bone regeneration (GBR) procedures, alveolar distraction osteogenesis, onlay bone grafting and the use of interpositional bone grafts [20, 22, 24].

GBR procedures have evolved greatly in the last two decades and have been prompted by the advent of prostheticdriven surgery, in which implant positioning and angulation are determined by the final, optimal prosthetic rehabilitation [38-40]. Standard GBR procedures entail the use of a long- 
lasting membrane to isolate the site and protect the clot. The membrane acts as a scaffold to facilitate the spread of osteoprogenitor cells and blood vessels and a physical barrier to epithelial and connective cell invasion from the surrounding soft tissues $[4,41]$. The success of GBR procedures is quite high, both in vertical and horizontal ridge augmentations, and compared with other augmentation techniques, they offer the advantage of being performable both before and simultaneously with implant placement. GBR has a high degree of predictability when some basic requirements are fulfilled. Factors of paramount importance for GBR success are appropriate flap closure and the use of long-lasting protective membranes. The flap closure must be maintained for the entire healing period and managed carefully, with passive coverage of the surgical zone and no residual tension left at the suture site $[20,21]$.

Grafting materials such as autogenous bone, demineralized freeze-dried allograft bone (DFDBA), and bovine deproteinized bone have been used to fill the space protected by the membrane and thus enhance the effectiveness of the technique [20, 22, 27, 32, 33, 42]. Simion in 2007 showed GBR procedures that used a 50:50 mixture of autogenous and bovine deproteinized bone below an e-PTFE membrane to be successful for the treatment of vertical atrophies, both in two-step and single-stage surgeries and with concomitant implant placement [43]. Other authors also later demonstrated the successful use of heterologous bone mixed with an equal amount of autogenous bone [31]. The rationale for mixing in the autogenous bone consists of adding to the biocompatible but still inert material live osteoprogenitor cells, differentiated osteoblasts, and possibly growth factors capable of supporting or stimulating bone regeneration. As far as the bone substitute being grafted is concerned, heterologous mammal-derived biomaterials are regarded as promising substitutes on the basis of the chemical identity of bone apatite and the high similarity in morphological parameters (i.e. trabecular density) that is encountered among mammals. Given such similarities, a mammal-derived bone graft should in principle interact properly with the bone cells (i.e. osteoclasts and osteoblasts) of the recipient site, showing remodeling at a nearly physiological rate and finally being replaced by endogenous, newly formed patient's bone [44, 45].

In the case presented here, a pre-hydrated, collagenpreserved heterologous biomaterial provided effective bone regeneration without being mixed with any autogenous bone. The implant was positioned following prosthetically driven principles, that is, based on the desired tridimensional position of the definitive prosthesis. In line with these principles, it was inserted in a slightly underprepared site, and its platform was aligned with an ideal line drawn $2 \mathrm{~mm}$ below the CEJ of the adjacent teeth. In order to minimize the overall invasiveness of the surgical procedure, a single-stage protocol was followed and the reconstructive GBR procedure was performed simultaneously with the implantation. This was made possible by the fact that the vertical bone defect was mild $(2-2.5 \mathrm{~mm})$, the edentulism was restricted to a small sector of the mandible, and the amount of graft necessary to fill the defect was limited, due to the volume taken up by the implant itself.
The histological analysis indicated that the graft material was biocompatible, since no fibrous tissue was found, and new vital bone formation occurred. The membrane appeared to act as an effective scaffold for colonization by bone cells and blood vessels, important precursors to bone regeneration. The extent of remodeling, even if assessed only qualitatively, was quite advanced. Only a small volume of biomaterial remained, compared to the newly formed bone volume. This is consistent with a possible physiologic rate of remodeling of the biomaterial in the graft site. It can be reasonably supposed that at a later stage, the remodeling could be complete. This result may be explained by the presence of endogenous bone collagen in its native state in the biomaterial that was used. Bone collagen is, in fact, a well-known activator or co-activator of many biological processes leading to bone regeneration [46-49].

The histologic results appear to correlate with the good clinical outcome documented by the intraoral x-rays. Indeed all follow-up controls showed complete maintenance of the peri-implant bone levels without any sign of bone resorption. The healed bone was perfectly stable up to 24 months after bone augmentation, supporting the functional loading of the implant. A possible explanation of the maintenance of bone levels and stability over time is the nearly complete resorption and substitution of the heterologous biomaterial by newly formed functional bone tissue together with the restoration of the masticatory load. The fact that control x-rays maintained the same appearance over time, showing the first implant threads in strict contact with a bone-like area, as far as both structure and radio-opacity are concerned, also suggests that the heterologous bone material may have undergone a remodeling process leading to the osseointegration of the fixture also in the biomaterial-only grafted region.

\section{CONCLUSION}

In the present case, heterologous biomaterial was used to regenerate a vertical ridge defect using a GBR technique with simultaneous insertion of a dental implant. The procedure entailed the use of a d-PTFE non-resorbable membrane and allowed for successful regeneration of the defect without the addition of any autogenous bone. The regenerated site was stable for up to 24 months after bone augmentation, and supported the functional loading of the implant. These results may be explained by the presence of native, unaltered bone collagen in the grafted material and appear to support the use of a heterologous biomaterial alone for vertical ridge augmentation by means of GBR techniques. Nevertheless long-term clinical studies are needed to confirm the positive effect of prehydrated corticocancellous porcine bone graft in enhancing the lasting stability of vertically augmented bone.

\section{CONFLICT OF INTEREST}

The authors confirm that this article content has no conflict of interest.

\section{ACKNOWLEDGEMENTS}

None declared. 


\section{REFERENCES}

[1] Atwood DA. Reduction of residual ridges: a major oral disease entity. J Prosthet Dent 1971; 26: 266-79.

[2] Atwood DA. Bone loss of edentulous alveolar ridges. J Periodontol 1979; 50: 11-21.

[3] Esposito M, Grusovin MG, Felice P, Karatzopoulos G, Worthington HV, Coulthard P. The efficacy of horizontal and vertical bone augmentation procedures for dental implants - a Cochrane systematic review. Eur J Oral Implantol 2009; 2: 167-84.

[4] Dahlin C, Linde A, Gottlow J, Nyman S. Healing of bone defects by guided tissue regeneration. Plast Reconstr Surg 1988; 81: 672-6.

[5] Buser D, Brägger U, Lang NP, Nyman S. Regeneration and enlargement of jaw bone using guided tissue regeneration. Clin Oral Implants Res 1990; 1: 22-32.

[6] Nyman S, Karring T, Lindhe J, Plantén S. Healing following implantation of periodontitis-affected roots into gingival connective tissue. J Clin Periodontol 1980; 7: 394-401.

[7] Karring T, Nyman S, Lindhe J. Healing following implantation of periodontitis affected roots into bone tissue. J Clin Periodontol 1980; 7: 96-105.

[8] Simion M, Scarano A, Gionso L, Piattelli A. Guided bone regeneration using resorbable and nonresorbable membranes: a comparative histologic study in humans. Int J Oral Maxillofac Implants 1996; 11: 735-42

[9] Simion M, Misitano U, Gionso L, Salvato A. Treatment of dehiscences and fenestrations around dental implants using resorbable and nonresorbable membranes associated with bone autografts: a comparative clinical study. Int J Oral Maxillofac Implants 1997; 12: 159-67.

[10] Hämmerle CHF, Jung RE. Bone augmentation by means of barrier membranes. Periodontology 2000 2003; 33: 36-53.

[11] Bottino MC, Thomas V, Schmidt G, et al. Recent advances in the development of GTR/GBR membranes for periodontal regeneration--a materials perspective. Dent Mater Off Publ Acad Dent Mater 2012; 28: 703-21.

[12] Rakhmatia YD, Ayukawa Y, Furuhashi A, Koyano K. Current barrier membranes: titanium mesh and other membranes for guided bone regeneration in dental applications. J Prosthodont Res 2013; 57: 3-14

[13] Sonick M, Hwang D. Implant Site Development. Hoboken: John Wiley \& Sons 2011

[14] Strietzel FP, Khongkhunthian P, Khattiya R, Patchanee P, Reichart PA. Healing pattern of bone defects covered by different membrane types--a histologic study in the porcine mandible. J Biomed Mater Res B Appl Biomater 2006; 78: 35-46.

[15] Yun J-H, Jun CM, Oh N-S. Secondary closure of an extraction socket using the double-membrane guided bone regeneration technique with immediate implant placement. J Periodontal Implant Sci 2011; 41: 253-8

[16] Al-Hezaimi K, Iezzi G, Rudek I, et al. Histomorphometric Analysis of Bone Regeneration Using a dual-layer of membranes (dPTFE placed over collagen) in fresh extraction sites: In: Canine Model. J Oral Implantol 2013. [Epub ahead of print].

[17] Al-Hezaimi K, Rudek I, Al-Hamdan KS, Javed F, Nooh N, Wang H-L. Efficacy of using a dual layer of membrane (dPTFE placed over collagen) for ridge preservation in fresh extraction sites: a micro-computed tomographic study in dogs. Clin Oral Implants Res. 2013; 24: 1152-7

[18] Carbonell JM, Martín IS, Santos A, Pujol A, Sanz-Moliner JD, Nart J. High-density polytetrafluoroethylene membranes in guided bone and tissue regeneration procedures: a literature review. Int $\mathrm{J}$ Oral Maxillofac Surg 2014; 43: 75-84.

[19] Hoffmann O, Bartee BK, Beaumont C, Kasaj A, Deli G, Zafiropoulos G-G. Alveolar bone preservation in extraction sockets using non-resorbable dPTFE membranes: a retrospective non-randomized study. J Periodontol 2008; 79: 1355-69.

[20] Buser D, Dula K, Belser U, Hirt HP, Berthold H. Localized ridge augmentation using guided bone regeneration. 1. Surgical procedure in the maxilla. Int J Periodontics Restorative Dent 1993; 13: 29-45.

[21] Buser D, Dula K, Belser UC, Hirt HP, Berthold H. Localized ridge augmentation using guided bone regeneration. II. Surgical procedure in the mandible. Int J Periodontics Restorative Dent 1995; 15: $10-29$.
Simion M, Jovanovic SA, Trisi P, Scarano A, Piattelli A. Vertical ridge augmentation around dental implants using a membrane technique and autogenous bone or allografts in humans. Int J Periodontics Restorative Dent 1998; 18: 8-23.

[23] Fontana F, Santoro F, Maiorana C, Iezzi G, Piattelli A, Simion M Clinical and histologic evaluation of allogeneic bone matrix versus autogenous bone chips associated with titanium-reinforced e-PTFE membrane for vertical ridge augmentation: a prospective pilot study. Int J Oral Maxillofac Implants 2008; 23: 1003-12.

[24] Dahlin C, Johansson A. Iliac crest autogenous bone graft versus alloplastic graft and guided bone regeneration in the reconstruction of atrophic maxillae: a 5-year retrospective study on costeffectiveness and clinical outcome. Clin Implant Dent Relat Res 2011; 13: 305-10.

[25] Schallhorn RG, Hiatt WH. Human allografts of iliac cancellous bone and marrow in periodontal osseous defects. II. Clinical observations. J Periodontol 1972; 43: 67-81.

[26] Quintero G, Mellonig JT, Gambill VM, Pelleu GB Jr. A six-month clinical evaluation of decalcified freeze-dried bone allografts in periodontal osseous defects. J Periodontol 1982; 53: 726-30.

[27] Zitzmann NU, Naef R, Schärer P. Resorbable versus nonresorbable membranes in combination with Bio-Oss for guided bone regeneration. Int. J Oral Maxillofac Implants 1997; 12: 844-52.

[28] Donos N, Lang NP, Karoussis IK, Bosshardt D, Tonetti M, Kostopoulos L. Effect of GBR in combination with deproteinized bovine bone mineral and/or enamel matrix proteins on the healing of critical-size defects. Clin Oral Implants Res 2004; 15: 101-11.

[29] Stavropoulos A, Kostopoulos L, Nyengaard JR, Karring T. Fate of bone formed by guided tissue regeneration with or without grafting of Bio-Oss or Biogran. An experimental study in the rat. J Clin Periodontol 2004; 31: 30-9.

[30] Donos N, Bosshardt D, Lang N, et al. Bone formation by ename matrix proteins and xenografts: an experimental study in the rat ramus. Clin Oral Implants Res 2005; 16: 140-6.

[31] Canullo L, Malagnino VA. Vertical ridge augmentation around implants by e-PTFE titanium-reinforced membrane and bovine bone matrix: a 24- to 54-month study of 10 consecutive cases. Int J Oral Maxillofac Implants 2008; 23: 858-66.

[32] Simion M, Baldoni M, Rossi P, Zaffe D. A comparative study of the effectiveness of e-PTFE membranes with and without early exposure during the healing period. Int $\mathbf{J}$ Periodontics Restorative Dent 1994; 14: 166-80.

[33] Tinti C, Parma-Benfenati S, Polizzi G. Vertical ridge augmentation: what is the limit? Int. J. Periodontics Restorative Dent 1996; 16: 220-9.

[34] Simion M, Fontana F, Rasperini G, Maiorana C. Vertical ridge augmentation by expanded-polytetrafluoroethylene membrane and a combination of intraoral autogenous bone graft and deproteinized anorganic bovine bone (Bio Oss). Clin Oral Implants Res 2007; 18: 620-9.

[35] Baljoon M, Natto S, Bergstrom J. Occurrence of vertical bone defects in dentally aware individuals. Acta Odontol Scand 2003; 61: 47-51.

[36] Peñarrocha-Diago M, Gómez-Adrián MD, García-García A Camacho-Alonso F, Rambla-Ferrer J. Vertical mandibular alveolar bone distraction and dental implant placement: a case report. J Oral Implantol 2006; 32: 137-41

[37] Urban IA, Jovanovic SA, Lozada JL. Vertical ridge augmentation using guided bone regeneration (GBR) in three clinical scenarios prior to implant placement: a retrospective study of 35 patients 12 to 72 months after loading. Int J Oral Maxillofac Implants 2009; 24: $502-10$

[38] Shanaman RH. The use of guided tissue regeneration to facilitate ideal prosthetic placement of implants. Int J Periodontics Restorative Dent 1992; 12: 256-65.

[39] Baird BB. Prosthetically guided implant placement for the surgical restorative team. Dent Implantol Update 1993; 4: 82-4.

[40] Saadoun AP, LeGall M, Touati B. Selection and ideal tridimensional implant position for soft tissue aesthetics. Pract Periodontics Aesthetic Dent 1999; 11: 1063-72.

[41] Dahlin C, Sennerby L, Lekholm U, Linde A, Nyman S. Generation of new bone around titanium implants using a membrane technique: an experimental study in rabbits. Int $\mathbf{J}$ Oral Maxillofac Implants $1989 ; 4$ : 19-25. 
[42] Nevins M, Mellonig JT. The advantages of localized ridge augmentation prior to implant placement: a staged event. Int J Periodontics Restorative Dent 1994; 14: 96-111.

[43] Simion M, Dahlin C, Rocchietta I, Stavropoulos A, Sanchez R, Karring T. Vertical ridge augmentation with guided bone regeneration in association with dental implants: an experimental study in dogs. Clin Oral Implants Res 2007; 18: 86-94.

[44] Zitzmann NU, Schärer P, Marinello CP, Schüpbach P, Berglundh T. Alveolar ridge augmentation with Bio-Oss: a histologic study in humans. Int J Periodontics Restorative Dent 2001; 21: 288-95.

[45] Schlegel KA, Fichtner G, Schultze-Mosgau S, Wiltfang J. Histologic findings in sinus augmentation with autogenous bone chips versus a bovine bone substitute. Int $\mathrm{J}$ Oral Maxillofac Implants 2003; 18: 53-8.
[46] Hsu FY, Chueh SC, Wang YJ. Microspheres of hydroxyapatite/reconstituted collagen as supports for osteoblast cell growth. Biomaterials 1999; 20: 1931-6.

[47] Reddi AH. Morphogenesis and tissue engineering of bone and cartilage: inductive signals, stem cells, and biomimetic biomaterials. Tissue Eng 2000; 6: 351-9.

[48] Griffith LG, Naughton G. Tissue engineering--current challenges and expanding opportunities. Science 2002; 295: 1009-14.

[49] Salasznyk RM, Williams WA, Boskey A, Batorsky A, Plopper GE Adhesion to Vitronectin and Collagen I Promotes Osteogenic Differentiation of Human Mesenchymal Stem Cells. J Biomed Biotechnol 2004; 2004: 24-34.

(C) Cucchi and Ghensi; Licensee Bentham Open .

This is an open access article licensed under the terms of the Creative Commons Attribution Non-Commercial License (http://creativecommons.org/licenses/by-nc/3.0/) which permits unrestricted, non-commercial use, distribution and reproduction in any medium, provided the work is properly cited. 